Preamble: The following contribution is written as a series of letters which reflect the process of email communication between the two authors. While this genre is not one normally used in an academic journal, for the purpose of conveying the iterative nature of this unfolding communication the letter format has been retained. Numerical referencing has been used in this work to minimise the interruption of in-text author/date referencing in the letter communications.

\title{
Conversations about Writing: The journey from practitioner to writer
}

\section{Dear Vaughan}

I am really glad to hear you are still enjoying working on your various writing projects. Your email prompted me to reflect on some of our discussions about that transition from practitioner to writer. It would be interesting to explore your experience of the writing journey and to look at how the academic and practice perspectives can complement one another, since we have both really benefited from this process of working together...what do you think? Delving into our experiences of writing for social work in this way might be useful for a broader audience even if it's a bit unconventional.

It's always possible that material in letters like ours might be considered (un)academic and therefore not worthy of publication... Even so when I read that editorial by Witkin in Social Work ${ }^{1}$, where he argues for different forms of writing to be included in social work journals, I just thought 'fortune favours the brave' and started writing this letter. I have to admit I was also intrigued with the notion of life imitating art and vice versa, in terms of working together to recreate the email discussion about writing that have unfolded between us. 
I firmly believe social work practice lends itself so well to creative, artistic activity, yet it is a dimension that gets lost in the hubbub and mayhem of day to day practice. So I look forward to corresponding more about our writing endeavours. With best wishes

Jane M

Dear Jane,

I have always been captured by the notion that social work is the 'art of the possible' and as social workers our task is to create opportunity and hope in the midst of uncertainty. This is really a challenge to creativity and soul. I have also realised in recent years that one way of making opportunities is to give voice to client stories through writing and introducing wider audiences to the experiences and issues we grapple with as we walk alongside our clients.

The period I spent from 1999 to 2004 with my office opening onto the food bank reception area at Presbyterian Support Otago convinced me of that. The sight, sound, and smell of poverty tugged at my heart every day and gave me courage and passion for social action. Since then writing has been a vehicle for those activities. Mind you, I am a bit of a slow learner as it took 30 years before I took the plunge to write for publication, with your encouragement. Looking back, there was a very gradual realisation that I spent a lot of time each day at work writing. As you know, my field of practice is management. I always seem to be busy doing reports, developing position papers or policy, arguing for resources. Write, write, and write. In fact one of the counsellors at Presbyterian Support Otago stuck his head in my office one day and said 'You're always writing. I’ve never known anyone to write so much.' That made 
me reflect on why did I write so much and inevitably led to the question of who was I writing for? However, as usual I am getting ahead of myself.

I am looking forward to exploring, knowing that in our way we will take the odd side road and have to clarify and tease out what the topic actually is - action reflection.

Write on.

Warm regards, Vaughan.

\section{Dear Vaughan}

You raised an interesting point about the purpose of writing in social work. Here in Australia the Practice Standards for social workers identify the need for practitioners to have competent skills in record keeping and report writing ${ }^{2}$. Of course any practitioner involved in policy development and analysis, or research must also be able to communicate their ideas with clarity, both verbally and in writing. Even so, the material I have seen about writing in social work does not commonly include professional and scholarly writing for publication as an area for practitioners to develop. ${ }^{3}$ An exception to this would have to be that book Professional Writing for the Human Services ${ }^{4}$ which was actually published some years ago in the United States. Currently in Australia we do not have an equivalent of that publication for social workers. This lack of focus on developing genres for writing about social work for a wider audience has led to academics ‘capturing' the journal publication market for showcasing research and practice developments. This may be a bit unfair as academics have to publish. Writing for publication is generally a task listed in their job descriptions and performance appraisals. Nevertheless, the proliferation of academic views in professional journals appears to swamp and somewhat 
disenfranchise practitioners in the field in terms of having their say. What do you think? I look forward to your views on this...

Best Wishes

Jane M

Dear Jane,

Your seemingly simple questions are always complex and multi dimensional! It is just as well social work practice is the equivalent of an advanced course in working through the complex until the simple emerges.

I'm not sure that I'd frame the predominance of academic publication as 'capture' or disenfranchisement. As you say academics have to publish research and material about practice development. It is part of their 'field' of practice. Social work practitioners on the other hand have to do the work with clients at whatever level they are operating. Most employers, and for that matter many practitioners, would not regard writing for publication as a priority in the practitioner's field of practice. The realities and pressures of workloads and expected outcomes for funding do not generally include recognition of writing as an activity, except for reports or policy. This general view means that practitioners who do write are likely to be doing it in their own time.

If I think of my own experience the turning point was when I began to see writing as a way of doing advocacy ${ }^{5}$. Suddenly this gave a purpose and legitimised the time and effort of writing - mind you I still did it in my own time, except for newspaper opinion pieces. At that point I was also at a personal and professional stage where I had the time and the energy to work on journal articles at home. 
I also think the other main barriers to practitioners are perhaps lack of encouragement and not knowing how to write for publication. If there is any disenfranchisement it is in the way articles have to fit an academic formula. The mystification of writing at the expense of telling what we do ${ }^{6}$. My initial approach to writing about my work as a practitioner in the field of social services management, was retrospectively symbolic of a perspective documented by my favourite author (of the moment), Reginald Hill. As he says in the Author's note of his book ' The Stranger House ${ }^{7} \quad$ " ...Despite the above disclaimers, it should be remembered that just as theologians and mathematicians use impossibilities, such as the square root of minus one or the transubstantiation of wine into blood, to express their eternal verities, so it is with writers and their fictions. In other words just because I've made it all up doesn't mean it isn't true'. For social work, and writing about social work you could say the reverse ‘just because it’s true doesn’t mean I didn’t make it up’. In my experience of social work truth is no stranger to fiction.

This insightful note from Hill certainly sums up how I felt writing about my work. I knew what I had done and how events unfolded, and found it hard to understand that for a professional article I had to somehow quote or use authorities that verified what I knew and experienced. As a practitioner you just get on and deal with the moment purposefully. If you're lucky or uncertain you might indulge in some research to see what other people have done, but generally you respond to what is unfolding with a mix of knowledge and what I call practice wisdom. In my view you should then be able to write about that and tell the story without having to show others have done it all before. Where is the magic of small steps and high drama? 
Having said all that, it was certainly interesting and developmental for me to follow a recipe for professional writing that made me find articles and books that supported and sometimes challenged what I had done or what I was asserting. Anyway, that was the first learning curve for me, that there was a method, a recipe, a formula that imposed some discipline on the practice of writing. Once I accepted that, it certainly worked both in terms of giving some form and rigour, but also it opened some broader horizons about access to information and the shared excitement of exploring possibility through the eyes of others. Exciting stuff, but hard work.

Much of the advocacy task of social work is in translating events and action and needs into the right language for the audience. So it's all about making those connections. With writing I struggled with the tension between using the article to reflect on what I had done, and the critical gaze of an unknown audience. First the editor and anonymous ' peer reviews', then the reader. In the end, the 'recipe' gives the mechanism for getting past the hurdle of the editor and gatekeeper. The reader is almost incidental as a silent supervisory audience... there for reflection in the space of a published work. So, I aim to reflect on what worked and consolidate and clarify my practice, to hopefully inform, to challenge, to advocate, and certainly to celebrate. It took me a long time though to get to the right space and place to write, and to recognize that writing is a vital field of practice in which practitioners need to claim their place alongside academics and researchers.

Last but not least, there was the powerful serendipity of your encouragement and mentoring. In many ways a writing partnership between an academic like yourself and 
a practitioner like me is an ideal model for collaboration. It combines the skills and knowledge of the academic and practitioner for the benefit of both as well as the clients.

Warm regards, Vaughan

\section{Dear Vaughan}

That was a very thoughtful and meandering reply to my questions and assertions about writing. In some ways it reminds me of our completely different styles for engaging in this business of writing. To use an analogy, you like to hop on a boat and see where it takes you, while I like to have studied the map and know exactly where we are going before we leave shore, and so it is with our approaches to writing. I actually think that was probably the greatest yet rewarding creative tension that we grappled with during the process of writing together. We both had to compromise with our own embedded style, yet in doing so we learned a great deal, well I did anyway. I feel like I can now stray a little from the 'recipe' we discussed, rather than slavishly adhering to it. If we were to write that recipe down what do you think it would look like? I am going to have a go, but please add or subtract as you see fit...

\section{Recipe for Joint Academic/Practitioner Writing}

Ingredients:

- Passion for the topic (to convey the subject area and information in an enthusiastic and engaging way)

- Equal proportions of practical, theoretical and research knowledge about the topic

- Clear structure for the written work

\section{Method}


Combine practice experience, theoretical knowledge and research findings until thoroughly mixed. Do not be afraid to add a dollop of passion to your mixture. Complete the article using a clear structure, with short sentences and writing to the precise guidelines of the intended journal. Proof read and check references before submitting. Do not be discouraged if your work comes back with comments from reviewers indicating areas for development. Working on these can frequently result in a better finished product.

Without seeming to be an apologist, the 'recipe' might look a little homespun, but the style does fit with my recent flourish of other artistic endeavours on the home front, such as the needlework and gardening. Let me know if you would add any ingredients or have any refinements on the method.

How is your writing of the 'Intervention Briefs' coming along?

Cheers

Jane

Dear Jane, I greatly enjoyed the 'recipe’ .The only thing I would add is 'leave to stand once mixed'. This is about patience and may relate to my style. As you say I like to get in the boat and get going but I have learnt that the process of writing is as important as the content. Ideas unfold, and while I am always impatient to get something onto the page, revisiting what is there is part of the process and craft. Small steps are part of social work and of writing, as Julia Cameron says 'just show up on the page’ ${ }^{8}$. Mary Pipher in her book 'Letters to a Young Therapist' ${ }^{9}$ says much the same quoting someone called Rosellen Brown ‘show up, pay attention, tell the truth and don't be attached to results.' In my mind this requires a patience and a willingness to take the 
first step, or rather write the first idea, then niggle away at it till it comes right - what you call 'interference'! Somehow or other this takes me to thinking about having the right place and space for writing. I like being where I can see the outside world and feel a connection to nature. This space creates a sense of relatedness or interdependence that goes beyond me and what's on my mind. I also like having natural light and a place where my books can be spread out a bit. I think working in the right place is part of helping me give voice, and is probably about the spirit or soulfulness of writing. What do you think?

Warm regards,

Vaughan

P.S The less said about the 'Intervention Briefs' for now the better. I will get back to them soon!!

\section{Dear Vaughan}

I have just received your letter and couldn't agree more with your addition to the recipe... to let the work stand for a while, that is so true. So often I have thought a piece of writing is completed, only to go back to it days, sometimes weeks later and find there is plenty to change. I see sentence structure errors that were invisible to me the first time around, and have quite often stumbled upon some additional idea or reference that adds something extra to the body of the work So yes, being patient and letting the work sit for a while before rereading and finally submitting the material for review is an important step that needs to be added to the method in the recipe. 
You wrote about this being the right time in your life and work to write, and about having a particular physical space that you like to set up your work. As I am writing this letter I look out on my back garden and so enjoy the sight of the roses in the late summer. I have found that having a good spot to write is always nice, but not absolutely necessary.

A few weeks back I was reading a story about the writer Asimov, who completed over 500 novels in his time. When he began writing he had no space in which to sit and write, and no time at all that was uninterrupted. He worked in his fathers shop and just scribbled down ideas and sentences in a notebook on the counter between serving customers and doing other tasks. Jane Austin was the same. She lived and worked in a busy Victorian household, and wrote her books a sentence or two at a time, when she had a moment to jot them down in a book she kept on the sideboard. ${ }^{10}$

I often have drafts of bits and pieces of articles and other writing projects that I take around with me in my bag, and when I have to wait for an appointment or find myself having a coffee at the cafe, it's a perfect time to just tune into these notes, even if it's just for a few moments. So I believe the notion that we need set blocks of dedicated time and the perfect spaces in which to write are just furphies that stop us from getting on with the job, or is that too harsh?

Cheers

Jane 
Dear Jane,

I think the important space for writing is the space in our minds, the unconscious processing which as you describe in your letter, leads you to be jotting as the mood, or rather the idea takes you. I have my writing journal that is usually close at hand for such moments. I often email a thought from work to home, to be teased at later. If I wake during the night I write the thought down so it is there in the cold light of day. The birth of writing has its own rhythm with a healthy disregard for conventional time.

Writers block is not something I have had to worry about as a writer/practitioner as I am writing to my own timetable in terms of work for publication. I am certainly conversant with blocks when writing under pressure, to deadlines at work. In my current job my monthly Board reports follow what I think of as the Calvin and Hobbes model. Calvin and Hobbes are a boy and his stuffed tiger in comic strips done by Bill Watterson ‘you can’t just turn on creativity like a faucet. You have to be in the right mood' says Calvin playing in the sandpit ' what mood is that ?' asks tiger Hobbes ‘last minute panic’ replies Calvin”11 So, in a very round about way I am reflecting that writing is a journey for me. Once an idea is in my mind, or a project or writing task started, the creative process is ongoing, whether I am writing or not. Often in the evolutionary stage my writing occurs in small bits and at odd times and places. There are other points as I firm up in my thinking, where I take the time to sit and write, usually for two to three hours at a stretch. Some days it is a struggle, on others the words flow. Often getting up and doing something else for a bit frees my mind enough that resumption is creative bliss. From what we have both written it is clear that to write is to struggle, and sometimes to fly. The obvious question is what drives you to write? 
I look forward to reading your response.

Warm regards,

Vaughan.

\section{Dear Vaughan}

What drives me to write? I haven't really thought too much about that, but off the top of my head it is an absolute love and passion for the work I am involved in, the quest to share, develop and generate ideas, and the associated reading about the practice and theory of others. Plus I have a love of books, in and of themselves. So writing for me is like an act of creativity, about teasing out ideas, speculating upon and testing ideas (that's where research comes in), and throwing ideas out to a wider audience for comment and exploration.

Now you have got me thinking about creativity, and its role in social work writing and practice. I suspect a lot of practitioners might say they are not in the least bit creative, but in fact most have to be able to think on their feet and respond quickly to changing and unpredictable circumstances. This capacity to adapt on the spot demonstrates a great deal of creativity, don't you think? In this way practitioners generate inventive ways of responding to difficult situations all the time, and that in my mind is very creative. Maybe practitioners are held back from writing by some of the 'myths' about being creative, like the one about having to have solitude and no distractions to be able to write?

If you have seen the film Love Actually ${ }^{12}$ you may remember there was a scene where the jilted lover took himself off to some beautiful place in the countryside to write his novel. He was living in a place with fantastic views, and had someone to do 
all his household chores? Well, I wish! And there's that other myth captured in your Calvin and Hobbs cartoon about having to wait until the mood strikes before you can write. Sometimes the process of just sitting at the computer and throwing the ideas down can bring on that mood, other times writing is just plain hard work. If I waited for the mood to strike in order to write I don’t think I would get much done.

Your description of writing a bit, scribbling notes, reading a bit and really working away at ideas while also doing other projects really rings true for me too. Sometimes when I am working on a task that is seemingly quite unconnected with writing I stumble across a resource or thread of an idea that opens up a whole new train of thought in my work. So I find working on a few different projects simultaneously actually stimulates and motivates my writing, rather than being a distraction. Finding connections between seemingly unrelated concepts has also been defined as an act of creativity ${ }^{13}$ and this happens all the time when I am writing, particularly when I am working with other people, who bring their own divergent thinking to the process. That element of the 'surprise discoveries' actually brings a great deal of joy to writing, don't you think, even when you are working on your own?

Cheers

Jane M

P.S I have been thinking about a title for our letters Vaughan...how does this sound? 'Conversations about writing. The journey from practitioner to writer'

Dear Jane,

Where to start in response to another of those letters of yours that poses so many questions and covers so much ground. Creativity? The heart of the matter really. I 
think there is a convergence between reflexive practice and the spiritual element of social work that centres on practice as creative and responsive. ${ }^{14}$ From this perspective to write about practice is doubly divine as the creative self within us flows onto the page and into an expressive form. ${ }^{15}$ Passion for practice is then transformed to the page and a wider audience. I can recall when I started thinking about writing that what I had to say was superfluous, ordinary and not of any great moment or interest. What I have come to realise is that it is this exploration of the ordinary in writing and story telling that is extraordinarily powerful. The notion of giving voice. I wholeheartedly agree that much of what social workers do is creative. As I said in an earlier letter I very much see our job as that of creating hope and optimism. It is hard work though. That's where I think it is the energy, time, confidence, and not knowing the recipe that is the writing barrier for practitioners, rather than the 'myths' of solitude or writer's block.

However, I think I am in danger of getting into a circular discussion, so time for a detour! I will finish with a quote from Mary Pipher that has been encouraging for me in writing, especially speeches around social justice and advocacy issues -

'there are many stories yet unborn. The best stories are those that help us see the complexities faced by others. We need stories to connect us with each other, stories to heal the polarisation that can overwhelm us all and stories to calm those who are frightened and who hate. These stories would offer us the possibility of reconciliation. We need stories that teach (children) empathy and accountability, how to act and how to be. Children are hungry for stories that help them feel hopeful and energetic. Let's turn off our appliances and invent these stories. Quilted together these stories will shelter us all' ${ }^{16}$ (p 271) 
The parallel for social work writing is, as you say, to be open to the joy of discovery across the academic, research and practice fronts, and have some fun in quilting these tales together.

Warm Regards, Vaughan.

P.S The title, Conversations about Writing, is a good one.

\section{Dear Vaughan}

That was a lovely message about the purpose of stories and story telling that you got from Pipher. In a way I hope these letters might convey something of our own story on learning to write for and about social work, and encourage others to have a go at writing about their practice too.

While I do get excited about writing and remain dedicated to it as a process for debating social work issues and connecting with others, I often get very little feedback about material I have had published, and I even wonder sometimes if anyone ever reads this stuff that has so tenderly and carefully made its way onto the page. Then, out of the blue an email will arrive with a query or idea about something I have written, and that doubt disappears in a twinkling. Just such a thing happened this morning. A student from Ireland emailed to talk about field education, and referred to something I had written years back. She wanted to discuss her own developing research in this field. This mornings email reminded me that writing about our work connects us into a global ‘conversation' about social work practice and research, and that can be pretty exciting and motivating. Have you had experiences like that Vaughan, when people have contacted you to follow up your work? 
I am glad you like the possible title for our series of letters. We can just work away at modifying it until we are both completely happy.

Kind Regards

Jane M

Dear Jane,

When I was young I used to enjoy skimming stones across rivers or lakes, and watching the ripples spread. In my limited experience so far, publishing is a bit like that really. You hope there is a ripple effect but you never quite know what goes on under neath the surface as a result of your work. You do know, one more pebble has been added to the ebb and flow of change. I have had some lovely isolated verbal feedback from colleagues, and one emailed query about my published work. I have found that once I have sent an article away, known it is accepted and then seen it in print, I am satisfied. I have done my bit. I am convinced the written word has power to challenge, persuade and transform. It is the essence of academia, bureaucratic systems, and policy development, and from that perspective an alchemical tool we need to use for effective practice.

I think the key thing I have learnt in all this scribbling is that 'writing practice' is a dimension of our art that adds purpose and meaning for the writer and client alike. Writing provides possibilities for different, powerful collaboration between academics, researchers and practitioners and a new partnership with clients. As Mary Pipher puts it 'writers and therapists live twice- the first time when they experience events, the second time when they use them in their work. ${ }^{17}$ Julia Cameron talks of 'righting by writing' in the context of reflecting on our journey and exploring the mysteries. ${ }^{18}$ We can claim our own stories. So taking the time to write has led me to 
the heart of imaginative and creative practice. A challenging and worthwhile field that is perfect for the post -modern world.

With warm regards,

Vaughan.

\section{Dear Vaughan}

Your response to my question about 'what's all this writing for anyway?' sums up so well the need to have faith in the writing process and patience with the outcomes in terms of making a contribution to social work. So much of what we do in practice defies precise measurement, including the impact of sharing our ideas and work in writing. Aren't we just so lucky to have this illusive quality as part of the wonderful magic and artistry embedded in practicing social work? It has been such a pleasure to correspond with you about our writing adventures, and I really hope that in some way through reading these letters other social workers might be encouraged to put pen to paper and share their own excitement and challenges about practice.

I wish you happy writing in the years ahead,

Jane M

\footnotetext{
${ }^{1}$ Witkin, S. (2000) Writing Social Work. Social Work 45 (5) 389-394

${ }^{2}$ Australian Association of Social Workers (2003) Practice Standards for Social Workers: Achieving Outcomes. Kingston.

${ }^{3}$ Prince, K. (1996) Boring Records?: Communication, speech and writing in social work. Jessica Kingsley Publishers. London

${ }^{4}$ Beebe, L. (1993) Professional Writing for the Human Services. NASW Press. Washington

${ }^{5}$ Jansson, B. (1999) Becoming an Effective Advocate: from policy practice to social justice. Brooks/ Cole Pub. Pacific Grove

${ }^{6}$ Hernandez, V., Dole, R., Chavkin, N. (2004) Writing Apprehension Among Social Workers: Addressing Internal and Structural Barriers to Writing About What We Do. Professional Development 7 (2) pp $52-60$

${ }^{7}$ Hill, R. (2005) The Stranger House. Harper Collins. London pviii

${ }^{8}$ Cameron, J. (1996) Vein of Gold. Pan Macmillan Ltd. Basingstoke p216
} 
${ }^{9}$ Pipher, M. (2003) The Art of mentoring. Letters to a Young Therapist. Basic Books. New York. p135

${ }^{10}$ Kelner, S. (2005) Motivate your writing. University Press of New England. Hanover \& London

${ }^{11}$ Watterson, W. (1993) 'The days are just packed', Time Warner Paperbacks. London. p82

${ }^{12}$ Curtis, R. (2003) Love Actually. Universal Studios

${ }^{13}$ Peterson, C. \& Seligman, M. (2004) Character, Strengths and Virtues. A handbook and classification. Oxford University Press. New York.

${ }^{14}$ Beddoe, L. (2004) Reflection in and critical reflection on social work: Learning about learning and thinking about thinking in social work. Social Work Review. VVI (4) pp50 -57

${ }^{15}$ Cameron, J. (1996) Vein of Gold. Pan Macmillan Ltd. Basingstoke p44

${ }^{16}$ Pipher, M. (1997) In the Shelter of Each Other. Rebuilding our Families. Ballantine Books NY p. 271

${ }^{17}$ Pipher, M. (2003) The Art of mentoring. Letters to a Young Therapist. Basic Books. New York p137

${ }^{18}$ Cameron, J. (1996) Vein of Gold. Pan Macmillan Ltd. Basingstoke p16 